\title{
A METHODOLOGICAL APPROACH FOR IMPLEMENTATION OF ADAPTIVE E-LEARNING
}

\author{
Valia Arnaudova ${ }^{1}$, Todorka Terzieva ${ }^{2}$, Asen Rahnev ${ }^{3}$
}

\begin{abstract}
The purpose of adaptive e-Learning is to ensure effective teaching by providing an opportunity for students to connect with an environment that suits their needs, behavior, and knowledge. The reason adaptive eLearning is important is that, for a learning process to be successful, it is necessary to consider teaching materials that address specific characteristics of the student, such as their particular goals, preferences, knowledge, and style of studying, to provide an appropriate teaching strategy.

In this article we present a methodological approach for implementing the adaptive e-Learning in the course "Computer information systems in tourism", offered to students in the program "Tourism" through the Smolyan affiliate of the Plovdiv University "Paisii Hilendarski”, using the Distributed Platform for e-Learning (DisPeL). The platform DisPeL enables a user to report on different aspects of the learning process, for example, the time each student takes to learn a specific topic from the curriculum, and the number of incorrect and correct answers from individuals as well as the entire group of students who were trained over a given period of time.
\end{abstract}

UDC Classification: 004.9 DOI: http://dx.doi.org/10.12955/cbup.v4.792

Keywords: e-learning, adaptive e-learning, adaptability in training, effective teaching.

\section{Introduction}

The advancement of systems that support the educational process in the direction of customizing and adapting the needs and knowledge of students is a contemporary area of development. An extremely important task is modeling the relationship between educational materials and resources, learning styles, and the assessment and assimilation of new knowledge.

In recent years, the creation and delivery of modules for adaptive educational content has become an important part of designing modern platforms for e-learning. Much research and development (Brusilovsky, 2012; Dagger, Wade, \& Conlan, 2005; Bontchev \& Vassileva, 2009; Stoyanov \& Popchev, 2014; Rahnev, Pavlov, \& Kyurkchiev, 2014a) have been aimed at customizing training systems to supporting users (students and trainers) and provide an environment for effective learning. The reason for the introduction of adaptive e-learning is that to have and effective learning process, some training materials are required. These materials are to be tailored to the different characteristics of the learner as specific objectives, preferences, knowledge, learning style and other individual factors to provide an appropriate pedagogical strategy.

The adaptive e-learning systems can better determine the level of initial training and the current status of knowledge and skills of every student. This allows teachers to choose the appropriate course materials, assignments, and exercises to increase training effectiveness, rationally.

The main goal of an adaptive e-learning system (regardless of the type of adaptation) is to provide effective learning by allowing students to communicate using e-learning systems according to their needs, behavior, and knowledge.

\section{Adaptability in training}

In essence, the idea of adaptive learning is not new. Its beginnings can be found even in the writings of (Carrier \& Jonassen, 1988). Over the years, this idea has been continuously expanded and enriched in parallel with the development of information technology. With the advent of e-learning there are different ideas for the realization of adaptive learning, from full control of the learning process to the

\footnotetext{
${ }^{1}$ Valia Arnaudova, Faculty of Mathematics and Informatics, Department of Computer Technologies, Plovdiv University

"Paisii Hilendarski“, Plovdiv, Bulgaria, valiaar@abv.bg

2 Todorka Terzieva, Faculty of Mathematics and Informatics, Department of Software Technologies, Plovdiv University

"Paisii Hilendarski“, Plovdiv,Bulgaria, dora@uni-plovdiv.bg

${ }^{3}$ Asen Rahnev, Faculty of Mathematics and Informatics, Department of Computer Technologies, Plovdiv University "Paisii Hilendarski“, Plovdiv,Bulgaria, assen@uni-plovdiv.bg
} 
concept of adaptive management that provides a wealth of information and diagnostic materials, to assisting students to make effective decisions about their own education (Kozlowski \& Bell, 2008).

Adaptive learning is a methodology, which periodically identifies knowledge and learning style, and then configures a specific set of learning resources, activities, and evaluation. It is designed for student needs and helps in better accumulation of new knowledge (Edmonds, 1987).

The aim of adaptive e-learning is to provide students the opportunity to master the materials prepared for study as well as provide additional material, depending on the student's interests and opportunities. Generally, the requirements for the adapted educational material are supplied to achieve the objectives assigned to the learning process (Velsen, 2008). As noted above, the purpose of the adaptive elearning is seemingly for students to absorb the teaching materials to their maximum ability, though the purpose of the education is more complex. Therefore, the adaptability of the system is divided into several categories:

- Mastering the material as much as possible;

- Satisfying the interests of the learner;

- Developing personal qualities and abilities of the learner;

- Objectives of psychological and social character.

Insufficient awareness of the actual level of a student's knowledge, as well as natural differences in their opportunities for learning, are the main reasons for the emergence of adaptive learning systems based on the didactic principle of individualization in learning. This principle is difficult to implement in traditional class-lesson training.

The main objective of an appropriate learning system is to provide efficient learning for the students, who may or may not have prior exposure to the subject content and may also be less experienced in reflecting their learning experiences due to limited prior academic instruction (Brusilovsky \& Peylo, 2003). Existing research has shown that application of adaptation through electronic learning systems can provide a better learning environment (Oppermann, Rashev, \& Kinshuk, 1997).

Adaptability in training under the modern scientific concept means individualizing the learning process on the basis of creating electronic courses that take into account an individual's characteristics, including their psychological traits, level of initial knowledge, levels of perception, goals, along with the training tasks. Adaptation can be viewed as adaptive planning (static adaptation) and interaction or dynamic adaptation. The implementation of adaptive planning in a student's education allows for adaptation in a group of students, to enable an individual student to develop specific skills and knowledge relating to specifically useful competencies. In the process of providing information, dynamic adaptation modifies the content in ways and forms to present educational and methodological materials and the overall management of adapting the system for each student.

According to (Stoyanov \& Kirschner, 2004), an adaptable e-learning system is an interactive system, which personalizes and adapts learning content, pedagogic models, and interactions between its users in order to satisfy users' requirements and preferences.

The advantages of adaptive e-learning are significant, and are continuously improving for presentation of teaching material. Constantly, creative systems to support learning and striving are increasingly being adapted in these systems for the needs of users, students, and teachers.

\section{Implementation of adaptive learning through DisPeL}

The Distributed Platform for e-Learning (DisPeL) is an integrated software system for automating the management, administration, and implementation of the learning process. The platform can be used in any institution that needs to provide or use electronic services in the field of education, e.g. universities, schools, private companies, public organizations, and other similar institutions (Malinova, Pavlov, \& Rahneva, 2014). The model components and services provided by DisPeL are detailed in Rahnev et al. (2014a). The DisPeL provides these five main services: administration of the educational process; Web audiences; adaptive learning content (adaptive electronic textbook); electronic testing and evaluation; and electronic services to support traditional proof testing and measurement. The distributed platform allows interaction with other software systems, regardless of the technologies used. This allows for future expansion and integration of the system. The DisPeL can improve the learning process by offering the following electronic services: 
- Automating of the process of administration;

- Maintenance of adaptive educational content;

- Electronic testing and evaluation;

- Support for traditional proof testing and evaluation.

A base element of the DisPeL is the presentation of structured and adaptive learning content, implemented in the module "Electronic textbook". In this article, we present a methodological approach for implementing adaptive e-Learning in the discipline "Computer information systems in tourism", which is offered for students in the program "Tourism" through the affiliate Smolyan of the Plovdiv University "Paisii Hilendarski", using the distributed platform for e-learning DisPeL.

As mentioned above, from Rahnev et al. (2014a), DisPeL achieves adaptability through the following:

- Continuous testing. At the end of every chapter of the learning content, the student is examined on the materials covered. The system assesses the answers and presents the student with a summary of identified gaps in his knowledge. The student can quickly navigate to the related part of the content to improve his knowledge on these areas. A unique learning procedure through the material is created for every student.

- Personalization. Students can personalize their learning content. Personalized elements are private for students, meaning their notes and highlights are visible only to the student who created them. This enhances the personal experience for every student. Personalization includes:

- Add notes. Notes are free textual content which can be embedded into the e-learning content. Within the e-learning content, notes are indicated with small icons. Clicking on an icon will open a popup window with the note, where the user can make changes, or delete the note.

- Emphasize content. Emphasis enables students to put a visual mark on a part of the text to quickly draw their visual attention when they next process the text. Emphasis is achieved with two tools: highlight and underline.

- Customize presentation of text. A person's successful perception of written text can be affected by the text size, contrast, line spacing, and font. Therefore the SYSTEM enables users to change the font and size of the font, line spacing, and background and foreground colors.

\section{Creating and using an electronic textbook in DisPeL}

The electronic textbook "Computer information systems in tourism" is offered for students in the program "Tourism" through the affiliate Smolyan of the Plovdiv University "Paisii Hilendarski", using the distributed platform for e-learning, DisPeL, and contains lecture teaching materials. The course's aim is to familiarize students with the basic stages of creating and maintaining websites and web-based applications. Initial concepts for web browsers, like the client-server systems, World Wide Web, multilayer architectures, and Web development tools are discussed. The modern standards for describing web content are studied in terms of tools for dynamic content management and building functional user interfaces with CSS and JavaScript. Students are provided with the basics of web programming and the techniques that support different browsers and devices. Contents include these components: an introduction to HTML; the HTML5 document structure; creating lists, tables, forms, and frames; inserting hyperlinks, dynamic and static images, and forms; and incorporating multimedia. It examines CSS in detail, focusing on CSS3 rules for presentation, fonts, backgrounds, frames, color, transparency, alignment, positioning, and views. Further, the basic elements of JavaScript and its functions, working with embedded objects, the definition of sites, details on event processing, access to elements of the website, and additional costs of JavaScript are discussed in terms of creating dynamic pages using the document object model (DOM). The lecture course materials include many practical examples.

The book includes tests after each lesson for both self-assessment and intermediate or final examination, which assess or verify the current status of students.

Later in this article the development and application of the e-textbook platform DisPeL is discussed. This focuses on providing structured adaptive content and placement of reports and statistics in the educational process. Results are presented and possible future development is recommended. 
The DisPeL defines an electronic book in terms of hypermedia electronic learning content for a given subject area and includes test questions on this content (Rahnev, Pavlov, Golev, Stieger, \& Gardjeva, 2014b). Every textbook has a title, author, co-authors, status ("ready", "outdated", or "under revision"), version (version number), tutorials (including tests), and final self-assessment tests. The electronic textbook "Computer information systems in tourism" in DisPeL provides structured content, with the textbook structured into 10 lessons (Figure 1).

Each lesson has a title, content including an introductory part and various headings, and finally, a test for the lesson. The DisPeL platform provides each teacher with the ability to customize the course according to the specifics of the discipline. At the end of each lesson, based on the educational content of the electronic textbook, the student is able to test their knowledge (Figure 2) of the studied material, and only on successful completion of the test is the educational content of the next chapter available.

Figure 1: The main topics of the course

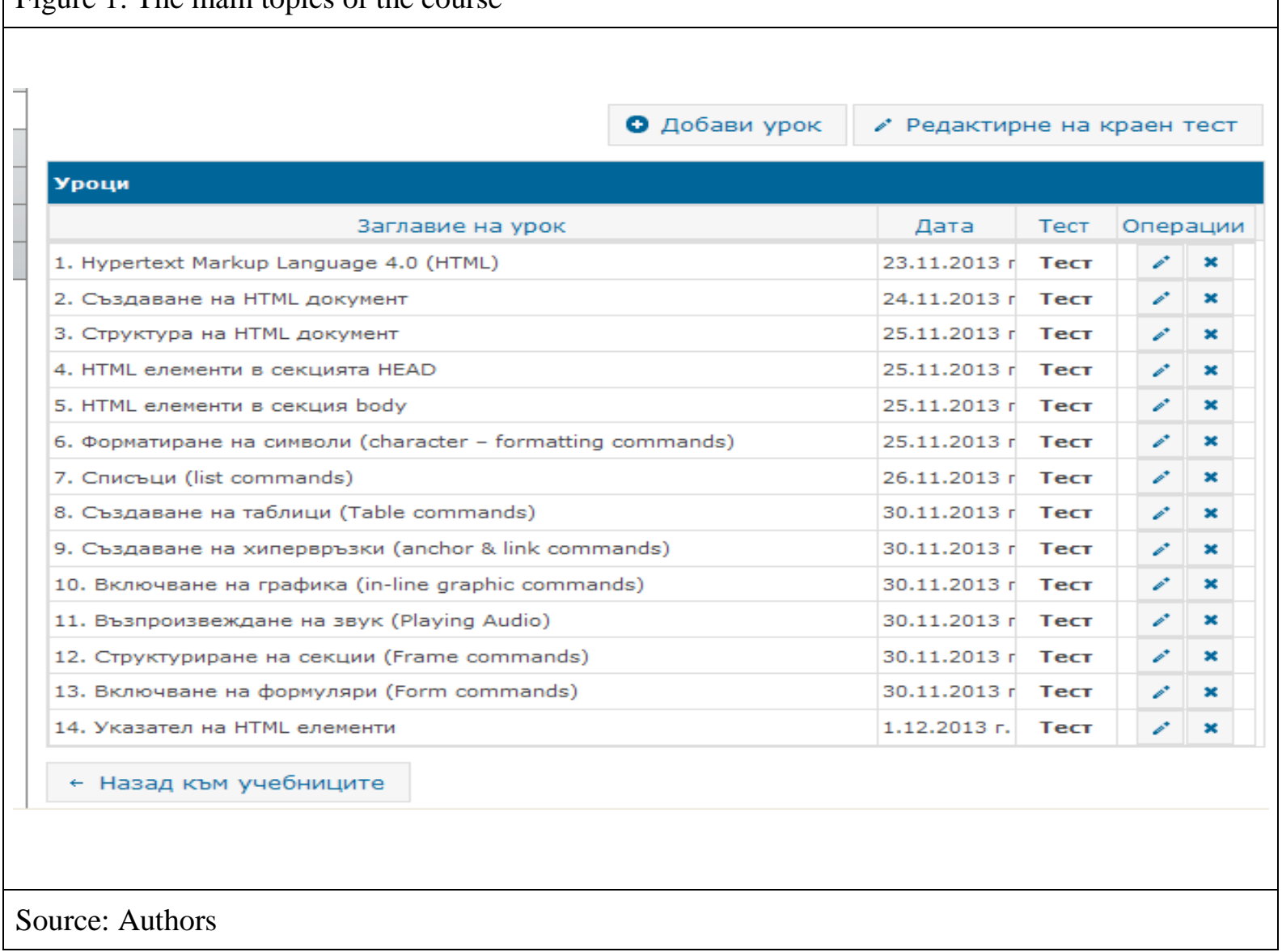

An effective test creation to revise acquired knowledge requires a sufficiently large base of unique test questions. The DisPeL allows a maximum number of unique tests to be prepared and caters for more than one possible correct answer (preferably at least two) and more than three (recommended 5) possible wrong answers. By combining enough correct and incorrect answers we can obtain a sufficient number of different outcomes to prevent students from learning the questions and the position of the correct answers. Generated questions like this can be used for intermediate tests after each lesson within the electronic textbook and for the final test at the end of training (Figure 3).

For intermediate tests, the system can be configured to require students to answer a few questions on the content of each lesson before they continue on to the next. Each test question has one right and three wrong answers randomly generated. If the student does not answer correctly, the teacher can set the system to analyze errors made by the student and redirect them to the relevant content, to "fill" gaps in knowledge. Each subsequent attempt to pass the test, involves the student answering newly generated questions. To create test questions after each lesson, the lecturer adjusts several parameters including the number of questions, i.e. how many questions will be asked of students in the test 
following the lesson. The total input of suitable test questions for lessons exceed this number in order to increase the total number of possible tests generated. The number of responses relates to how many possible answers will be chosen for each question and feedback is given for the student with a wrong answer to redirect them to the information in the lesson.

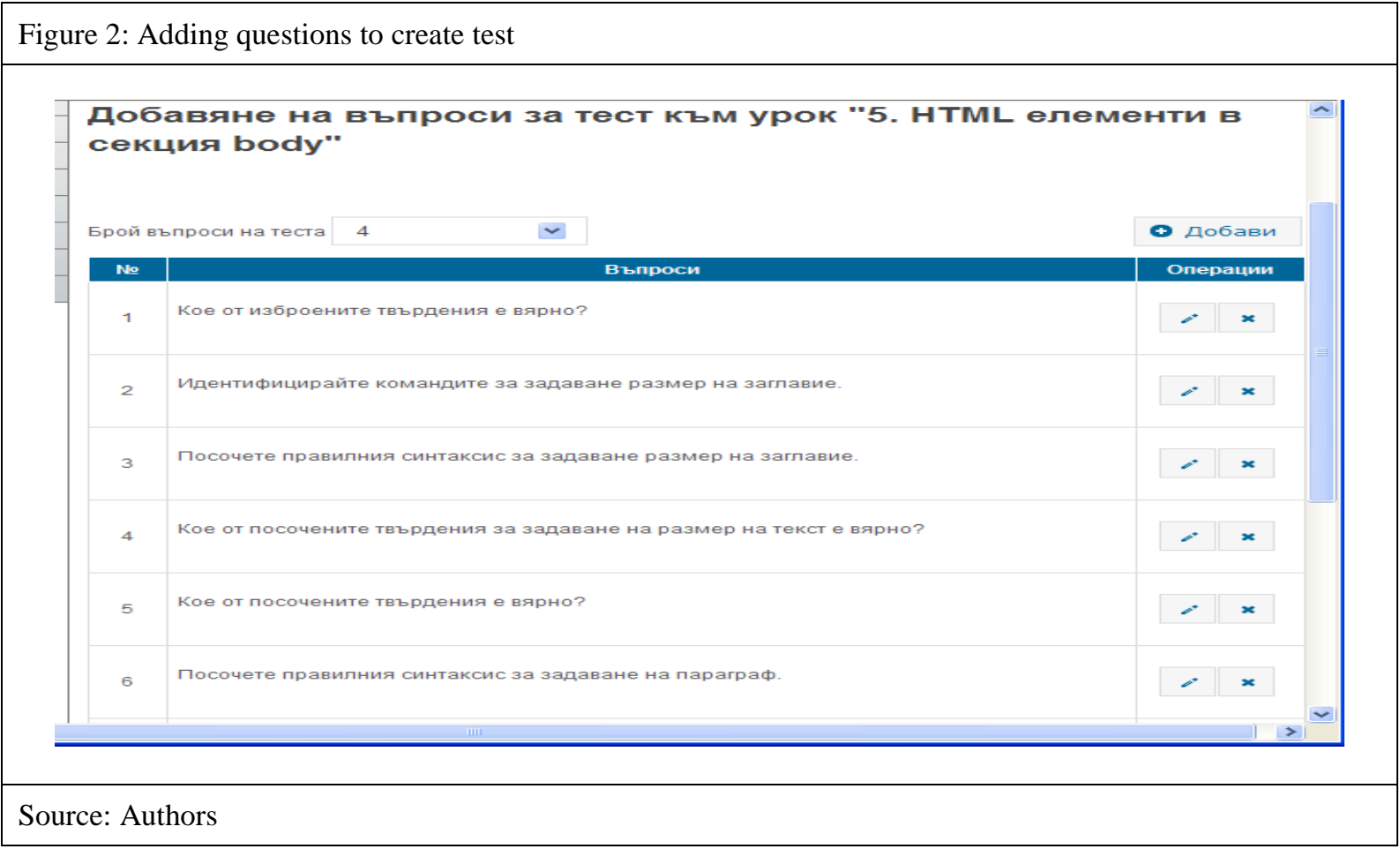

Figure 3: Creating the final test

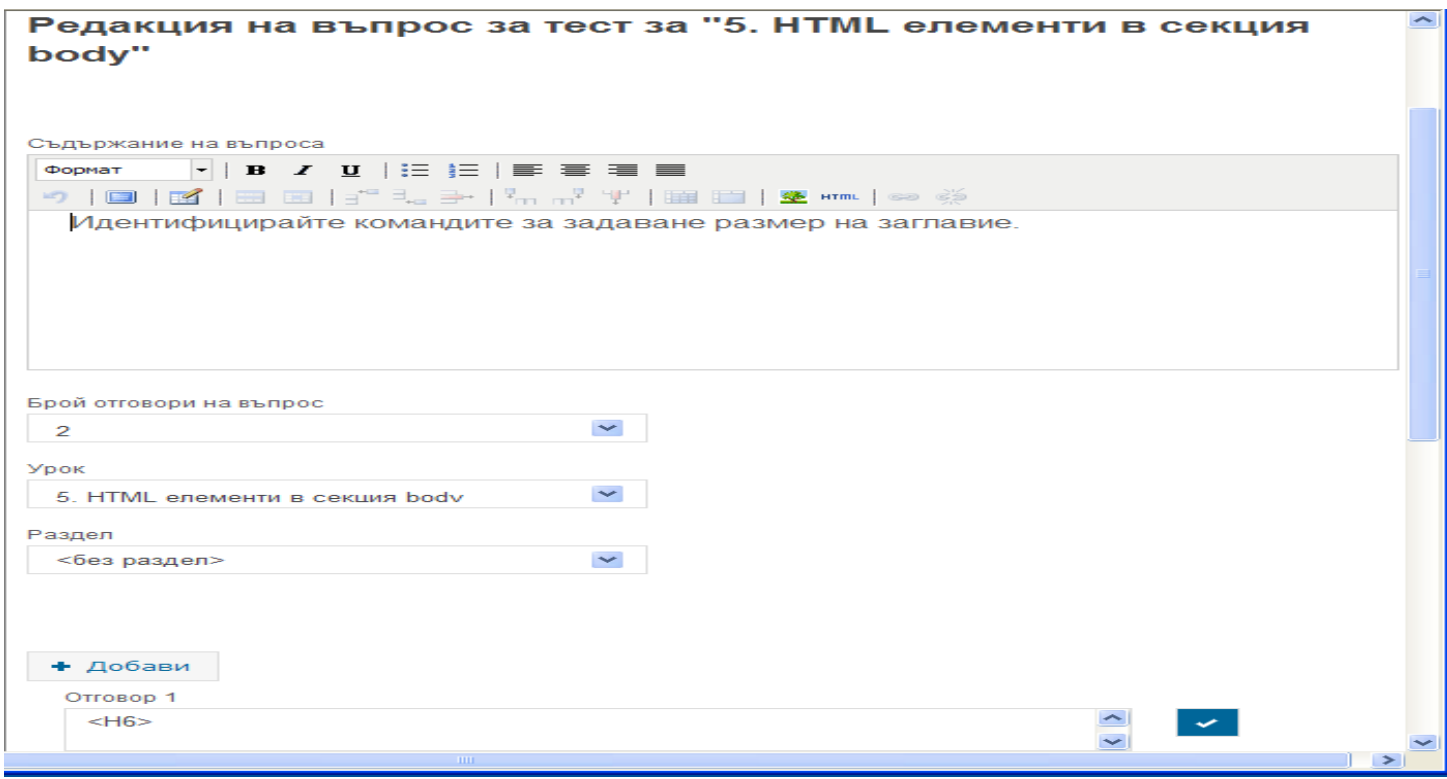

Source: Authors

The approach involved in achieving adaptive e-learning content in the DisPeL comprises repeated testing and monitoring of the student's progress, the personalization of content, and an adaptive presentation. The presentation of educational content is strictly linear. In this way, a unique learning process for each student is achieved, mainly through test questions. At the end of each lesson, based 
on the educational content of textbooks, students are tested on the material they have studied and only on successful completion of the test can they proceed to the educational content of the next lesson. For every individual student, the DisPeL evaluates responses and provides information based on a presumed absence of knowledge. In creating tests in the e-textbook, the objective is for each student to receive a unique set of test questions, based on material from the preceding lesson, that can be answered regardless of how many returns the student makes to the lesson material. The tests require a sufficient number of test questions; the creation of which is laborious and takes considerable time. The DisPeL provides an algorithm that allows for a minimum number of unique test questions that is more than the required number of responses, and generates a unique base of test questions and exam tests for each student (Rahnev et al., 2014b).

For intermediate tests, the electronic textbook requires students to answer at least four test questions on the material in each lesson before continuing to the next lesson. For each test question, on a random basis, one correct and three wrong answers are chosen. If the student does not answer correctly, the system analyzes the errors and redirects the learner to the relevant content, and thereby creates a unique learning path for each student. The hyperlink is localized to the site of the lesson, which gives information about the matter. Upon completing the same test, the student receives four new questions, selected at random, again as a set of questions with proposed options for answers.

\section{Analysis of learning outcomes}

The developed electronic textbook "Computer information systems in tourism" has been successfully applied in the training of students majoring in "Tourism" at the Faculty of Economy and Social Studies at the Smolyan affiliate of the Plovdiv University "Paisii Hilendarski" during the academic year 2014-2015. The platform DisPeL enables a user to report on different aspects of the learning process, for example, the time each student takes to learn a specific topic from the curriculum, and the number of incorrect and correct answers from individuals as well as the entire group of students who were trained over a given period of time.

The system allows a student profile to be created. For each student who uses the electronic textbook, the system traces the subjects they have read over the time allocated for self-study, as well as the statistics on intermediate and final tests that are conducted independently or by the teacher. Figure 4 shows a sample of information on lesson progress, and Figure 5 of reference to students.

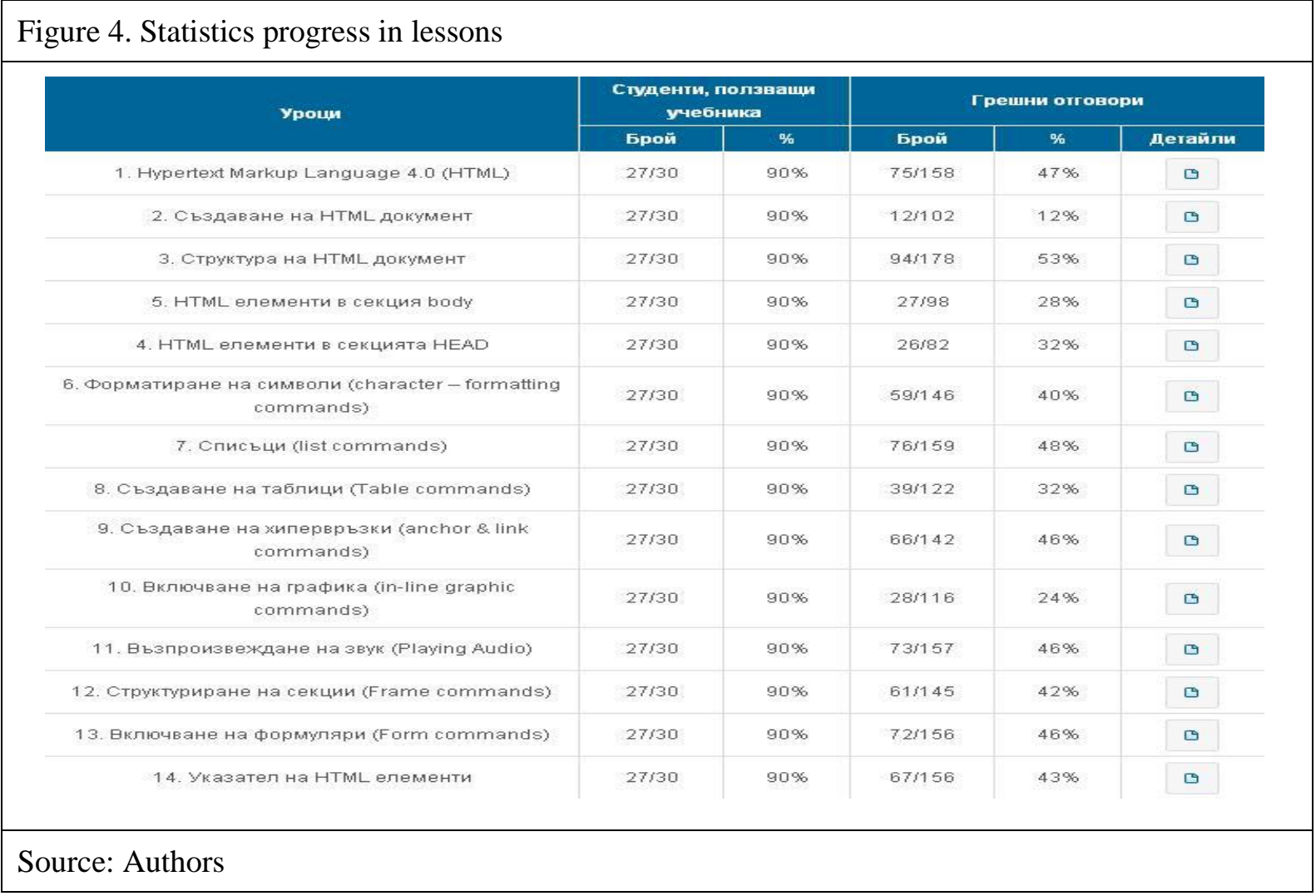


After completing the test, the system outputs a list of the incorrect and correct answers given by each student for each question. The incorrect answers are displayed with a red background. Also, the system displays the number of test questions and the number of correct answers given by a student. This allows students to see their mistakes and gain real insight into their performance in the test.

One of the possibilities that the system provides is statistical information on exams conducted to date. In this way, the teacher can make personal summaries for a particular student or group of students, and allow them to ascertain how well the teaching material is being assimilated for different topics within a given discipline. Also, the teacher can easily compare test scores for certain subjects over different years. Thus, a teacher can follow the extent of change in the methodology of teaching and various teaching strategies and how these affect students in acquiring their knowledge and skills.

Figure 5. Statistical summary for each student

\begin{tabular}{|c|c|c|c|c|c|c|}
\hline \multirow{2}{*}{ Факулт. № } & \multirow{2}{*}{ Имена на студент } & \multicolumn{2}{|c|}{ Ирочетени уроци } & \multicolumn{3}{|c|}{ Трешпни отговори } \\
\hline & & Брой & $\%$ & Брой & $\%$ & Детайли \\
\hline 124101 & ГАБРИЕЛА СТОЯНОВА ЩЪРБАНОВА & 14 & $100 \%$ & 57 & $50 \%$ & - \\
\hline 124033 & ЕВЕЛИНА ДИЛЯНОВА КЕЧЕВА & 14 & $100 \%$ & 21 & $26 \%$ & - \\
\hline 124102 & КАПОЯН ДЕЛЧЕВ ЖЕЛЕВ & 14 & $100 \%$ & 70 & $56 \%$ & o \\
\hline 124103 & ОЛГА АСЕНОВА БОНКАЛОВА & 14 & $100 \%$ & 36 & $37 \%$ & o \\
\hline 124104 & ВЕНЦИИЛАВ ФИДАНОВ ТЕРЗИЕВ & o & $0 \%$ & o & $0 \%$ & ○ \\
\hline 124108 & МЕХМЕТ АЛИЕВ ТАХИРОВ & 14 & $100 \%$ & 49 & $47 \%$ & o \\
\hline 124113 & ЕЛВИРА КРАСИМИРОВА БУНДЕВА & 1 & $7 \%$ & o & $0 \%$ & $\circ$ \\
\hline 124115 & АННА БИСЕРОВА КОЛЕВА & 14 & $100 \%$ & 53 & $49 \%$ & ○ \\
\hline 124117 & НИКОЛА ЛЮБЕНОВ ПАНАЙОТОВ & 14 & $100 \%$ & 40 & $41 \%$ & - \\
\hline 124118 & ДИМИТЬР ЮЛИЯНОВ АРНАУДОВ & 14 & $100 \%$ & 32 & $36 \%$ & o \\
\hline 124119 & РУМЕН ЕМИЛОВ ИВАНОВ & 14 & $100 \%$ & 72 & $56 \%$ & D \\
\hline 124121 & КАЛИН РОСЕНОВ ГЕОРГИЕВ & - & $0 \%$ & o & $0 \%$ & b \\
\hline 124122 & ВЕСЕЛИНА СТЕФАНОВА ИЛИЕВА & 14 & $100 \%$ & 46 & $42 \%$ & o \\
\hline 134101 & МАРИЯ АНГЕЛОВА ПЛАШИМЕЧКОВА & 14 & $100 \%$ & 57 & $50 \%$ & - \\
\hline 134104 & АКСИНИЯ БАНКОВА ХАДНКИЕВА & 14 & $100 \%$ & 55 & $48 \%$ & o \\
\hline 134107 & ОКСАНА СЪЕИНОВА ТОМАШОВА & 14 & $100 \%$ & 26 & $32 \%$ & D \\
\hline 134126 & $\begin{array}{l}\text { АЛЕКСАНДРИНА КИРИЛОВА } \\
\text { МИНДЕВА }\end{array}$ & 14 & $100 \%$ & 13 & $19 \%$ & o \\
\hline \multicolumn{2}{|c|}{ Среден резултат: } & $11,59 / 14$ & $81 \%$ & $627 / 1434$ & $44 \%$ & \\
\hline
\end{tabular}

\section{Conclusion}

The improvement of systems supporting the educational process in the direction of customizing and adapting to the needs and knowledge of trainees is a contemporary area of development.

The other side to this training, namely the preliminary hard work of the teacher, should not be overlooked. The initial development of an electronic course requires more time and effort than the classical educational course, and the effort in developing interactive e-content is larger still and sometimes requires additional skills and teamwork.

Regardless of the negative aspects, the advantages of adaptive e-learning are significant and are continuously developing. In recent years, the techniques and means of presenting educational content has incessantly advanced. Ultimately, the goal is to establish more accountability and improve teaching. This methodological approach stimulates students by giving them the opportunity, through self-study, to actively define their individual pace of learning. The use of adaptive systems for elearning allows:

- customized training, or individualized learning plans;

- implementation of various teaching strategies;

- accumulation of information for students and teachers that is analyzed statistically for different indications. This allows rational feedback and dynamic change in the training technology; and

- an individualized approach for students and the ability to adapt the difficulty level to the needs of the student. 
Still to be examined is an extremely important task of modeling the relationship between educational materials and available resources, learning styles, and assessment and assimilation of new knowledge.

\section{Acknowledgements}

Parts of this work are supported by a project IT15-FMIIT-004 of the Scientific Research Fund of Plovdiv University "Paisii Hilendarski”, Bulgaria.

\section{References}

Bontchev, B., \& Vassileva, D. (2009). Adaptive courseware design based on learner character, Proc. of Int. Conf. on Interactive Computer Aided Learning (ICL2009), 23-25 Sept., 2009, Villach, Austria, pp. 724-731.

Brusilovsky, P. (2012). Adaptive Hypermedia for Education and Training. In: Adaptive Technologies for Training and Education, Cambridge University Press, Cambridge, UK, 46-68. ISBN: 9780521769037.

Brusilovsky, P. \& Peylo, C. (2003). Adaptive and intelligent Web-based educational systems. International Journal of Artificial Intelligence in Education 13 (2-4), Special Issue on Adaptive and Intelligent Web-based Educational Systems, 159 172.

Carrier, C. \& Jonassen, D. (1988). Adapting courseware to accommodate individual differences. In book Instructional design for microcomputer courseware, pp. 61-96, Lawrence Erlbaum Associates, New Jersey, 1988.

Dagger, D., Wade, V. \& Conlan, O. (2005). Personalization for All: Making Adaptive Course Composition Easy, Special issue of the Educational Technology and Society Journal, IEEE IFETS.

Edmonds, E. (1987). Adaptation, Response and Knowledge. Knowledge Based Systems, 1(1), pp. 3-10.

Kozlowski, S. W. \& Bell, B. (2008). Team learning, development, and adaptation. Group learning, pp. 15-44.

Malinova, A., N. Pavlov \& Rahneva, O. (2014). The electronic textbook "Developing business web applications" in the Dispel Platform, Proc. of International Conference "From DeLC to Velspace", Third Millennium Media Publications, Plovdiv, Bulgaria, pp. 183-190, ISBN: 0-9545660-2-52014 (in Bulgarian).

Oppermann, R., Rashev R. \& Kinshuk, A. (1997). Adaptability and adaptivity in learning systems. Proceedings on Knowledge Transfer, 1997, Vol. II, pp. 173-179.

Rahnev, A., Pavlov, N. \& Kyurkchiev, V. (2014a). Distributed Platform for e-Learning - DisPeL, European International Journal of Science and Technology (EIJST), Vol. 3, No. 1, pp. 95-109, ISSN: 2304-9693.

Rahnev, A., Pavlov, N., Golev, A., Stieger, M. \& Gardjeva, T. (2014b). New Electronic Education Services Using the Distributed E-Learning Platform (DisPeL), International Electronic Journal of Pure and Applied Mathematics (IEJPAM), Vol. 7, No. 2, 2014, ISSN: 1314-0744, 63-71.

Stoyanov, S., \& Kirschner, P. (2004). Expert Concept Mapping Method for Defining the Characteristics of Adaptive ELearning: ALFANET Project Case. Educational Technology, Research \& Development, Vol. 52, No 2, 2004, pp. 41-56. Stoyanov, S. \& Popchev, I. (2014). DeLC - Past, present, future. Plenary talk, Proc. of International Conference "From DeLC to Velspace", Third Millennium Media Publications, Plovdiv, Bulgaria, pp. 29-40, ISBN: 0-9545660-2-52014 (in Bulgarian).

Velsen, L. (2008). User-centered evaluation of adaptive and adaptable systems: a literature review, The Knowledge Engineering Review Journal, Cambridge University Press, Vol. 23:3, pp. 261-281. 